\title{
Discussion on the Application of Geographic Information System in Urban Ecological Environment Management under the Background of Big Data
}

\author{
Qinfen Zheng \\ Southwest Minzu University, Chengdu, China \\ Email:1136762548@qq.com
}

How to cite this paper: Zheng, Q.F. (2020) Discussion on the Application of Geographic Information System in Urban Ecological Environment Management under the Background of Big Data. Open Access Library Journal, 7: e6904.

https://doi.org/10.4236/oalib.1106904

Received: October 14, 2020

Accepted: November 6, 2020

Published: November 9, 2020

Copyright $\odot 2020$ by author(s) and Open Access Library Inc.

This work is licensed under the Creative

Commons Attribution International

License (CC BY 4.0).

http://creativecommons.org/licenses/by/4.0/

\section{(c) (i) Open Access}

\begin{abstract}
Urban ecological management in the context of big data space is an objective need for urban development. The ecological environment of a city is a comprehensive group of various ecological factors and ecological relationships that people in urban areas rely on for survival, development, and evolution. Geographic information is performed on the effective management of system technical means. Predictive decision-making and analysis can be made by processing urban spatial data, urban resources, and spatial analysis. This can improve management capabilities in improving and optimizing urban management, planning, and construction so as to make cities and humans develop better.
\end{abstract}

\section{Subject Areas}

Big Data Search and Mining, Ecology, Environmental Sciences, Information Science

\section{Keywords}

Big Data, Urban Ecological Environment Management, Geographic Information System

\section{Overview}

\subsection{Big Data Background}

With the close integration of technologies such as the Internet of Things, social 
networks, and cloud computing with all aspects of life, and the rapid development of existing technologies in computing, storage, and networking, the accumulated, growing, and accumulated data of human beings are exponentially increasing. The earliest reference to the term "big data" can be traced back to the open source project Nutch of apache org. At that time, big data was used to describe a large number of data sets that needed to be batch processed or analyzed at the same time to update the web search index. Data is not an accurate term. It has become a description of the endless accumulation of various types of data [1]. In 2011, the American consulting company McKinsey defined in its report on big data: data whose size exceeds the ability of conventional database tools to acquire, store, manage and analyze [2]. Big data promotes urban problem analysis, spatial simulation analysis, and urban management decision-making and evaluation. Weibo data, mobile phone data, spatial data, building information, etc. can all become the basis for analysis and simulation. Big data provides a large amount of data with geospatial information and provides a new scientific basis for all aspects of urban management. Using technology platforms to analyze the geospatial information has become an important means of urban management.

\subsection{Urban Ecological Environment Management}

Urban ecological environment management is based on the systematic analysis of the structure of the urban ecological system, using ecology, management, sociology, economics and other multidisciplinary theories to form a set of measures aimed at protecting the integrity, sustainability and coordination of the urban ecosystem: An urban management method for ecological environment protection [3]. Compared with traditional management methods, urban ecological environment management emphasizes the protection and development, utilization and coordination of ecosystems. On this basis, it is not only necessary to maintain the development of urban ecosystems, but also to fully protect the service functions of natural ecosystems.

The urban ecological environment is a natural or social environment with unique structure and characteristics and occupying a specific geographical space. It is a complex giant system. It is generally regarded as the urban natural ecological environment and the urban social ecological environment. The research object of the former is mainly non-biological factors, such as geology, landform, climate, etc.; biological factors, such as biodiversity, biological impact on habitat, etc. The latter social ecological environment mainly refers to the nature and level of human intervention in the natural environment [4]. Taking social ecological environment as the main research object, it mainly includes: 1) land carrying capacity and population issues; 2) water resources management; 3) type and degree of ecological damage; 4) environmental pollution and environmental pollution forecast analysis; 5) economic structure and economic and social development level. 


\section{Geographic Information System}

\subsection{Geographic Information System}

Geographic Information System originated in the 1960s, and then quickly set off a research boom. Roger Tomlinson (1966), the father of Geographic Information System, first proposed that Geographic Information System is a digital system for comprehensive analysis and manipulation of geographic data. At present, many domestic scholars are more inclined to the United States Federal Digital Map Coordination Committee on the definition of geographic information system: geographic information system is supported by computer hardware and software systems and different methods, to the whole or part of the earth's surface (including the atmosphere). A technical system for collecting, storing, managing, computing, analyzing, displaying and describing geographically distributed data in the space to solve complex planning and management problems. The main function of geographic information system is to manage and analyze spatial data, so it is widely used in the field of spatial data and spatial information.

\subsection{Overview of the Application of Geographic Information System in Urban Ecological Environment Management at Home and Abroad}

Foreign countries used geographic information system platforms to manage the urban ecological environment for an earlier period. A representative example is Milwaukee. The city began to study the establishment of geographic information system systems in 1974. Map update, zoning, elections, tax management, housing management, water resources management, population size forecasting, land carrying capacity, public health management (lead poisoning), garbage removal and other aspects of urban management. Beginning in 1974, the National Science Foundation of the United States and some companies established long-term research projects on the "Urban Information System". The National Census Bureau introduced the DIME data format through geocoding, and later launched TIGER digital products to further integrate geocoding and Combine the digitized census base map. People use the census data provided by the National Census Bureau (population density, age composition, occupational status, economic income level, municipal facility status, real estate information, etc.) to improve municipal facilities, transform traffic conditions, predict and predict urban population models. Both the carrying capacity of environmental resources and sustainable development play an important role.

The initial research of domestic geographic information system began in the early 1980s, mainly based on the research institutions of the Chinese Academy of Sciences and some universities. In 1987, the Ministry of Construction held a special experience exchange meeting on the application of new technologies by the urban planning department in Kunming, which promoted domestic The development of geographic information system began in 1996 to establish the per- 
formance test of my country's geographic information system software and the establishment of a geographic information system demonstration project system to promote the development of my country's GIS in the direction of industrialization. According to incomplete statistics, the four municipalities directly under the Central Government of Beijing, Shanghai, Tianjin, and Chongqing have established basic geographic information systems, and the first three cities have also established urban planning management information systems. Most cities first establish a basic geographic information system [5]. At the same time, according to needs, select some urgent problems to establish subsystems, such as: urban ecological environment management, urban planning management, comprehensive management of underground pipe networks, municipal facilities and telecommunications, electricity, gas, heating, water supply and drainage, transportation, Individual professional systems such as fire protection.

\section{Application of Geographic Information System in Ecological Environment Management}

In the context of big data, data types are rich and diverse. Based on geographic information systems, a comprehensive analysis and dissection of the main characteristics, problems, and comprehensive evaluation of urban ecological environmental management under certain conditions are conducted to provide scientific basis for urban ecological management.

\subsection{Land Carrying Capacity and Population Issues}

Geographical information systems have effective applications in land carrying capacity and population issues. Urban land carrying capacity is within a certain area. The current urban resources can meet the ability of people to survive, live and produce at a certain population size. Land in the era of big data Resource survey and population survey data are easier to obtain. For example, it is possible to comprehensively use productivity estimation models, crop remote sensing estimates, and quantitatively analyze and calculate the relationship between population, food, land and living standards through field surveys, observations, and statistical analysis. Under the conditions of land production potential, the population carrying capacity of land resources and the comprehensive carrying capacity of land are studied [6].

\subsection{Water Resources Management}

In our country, many cities have established GIS-based water resources management systems. For example, the Beijing Water Resources Management Geographic Information System was put into operation in April 2002. ESRI, a well-known geographic information system development company in the United States, established a groundwater geographic information system to manage groundwater pollution when conducting surveys of groundwater pollution in California, and established a GIS-based groundwater simulation model to ex- 
change hydrogeological databases and model data through the geographic information system, So as to conduct groundwater pollution management and evaluation [7]. Geographic information system has been widely used in water resources planning, water resources management and evaluation and other fields. In urban ecological management, geographic information systems can evaluate water resources based on comprehensive urban water system data. Some experts and scholars are committed to water environment quality assessment management systems. After the grid data expression form of the geographic information system is established, watersheds are formed. Rainfall runoff model, this method can also be used to assess the disaster situation of mountain floods, and carry out quantitative assessment of the progress of the disaster situation. China has developed water resources. Under the big data preprocessing mechanism, water resources management based on geographic information systems is more important [8].

\subsection{Type and Extent of Ecological Damage}

In the management of the urban ecological environment, the main factors of urban ecological damage are those in the social ecological environment. Li Hongwang uses geographic information system-based high-speed railway ecological impact assessment and ecological restoration research, through the three aspects of natural ecology, social ecology and landscape The ecological impact factors of high-speed railways were analyzed, and the evaluation index system of ecological impacts of high-speed railways was established [9]. Soil erosion is one of the major problems facing my country, and it is also one of the most serious types of ecological damage in my country. The geographic information system analyzes the soil erosion and surface erosion by sorting out the vegetation coverage, the stability of the bank foundation, the density of the valley, the water flow, the buffer zone of the water system, and the type of land use in the relevant study area, so as to obtain the degree of soil erosion in the study area. Further strengthen the urban ecological environment protection. In the distribution area of key biological populations in the city, analyze the key protected areas in the city by studying animal migration paths, animal habitat selection, animal population surveys, animal community and habitat status assessment and monitoring, and city viability analysis. The degrees of threat to biological populations, etc., establish a comprehensive geographic database of species distribution to protect the urban ecological environment [10].

\subsection{Environmental Pollution and Environmental Pollution Forecast Analysis}

Most people suffer from environmental pollution without knowing it. Therefore, the early warning mechanism of the model established by scientific data indicators is very necessary. It is also necessary to focus on the analysis of the type, cause, status and development trend of environmental pollution, and The rela- 
tionship between environmental capacity. For example, a geographic information database of major urban air pollution is established from urban data, and emergency plans are determined through quantitative analysis and simulation of the state after air pollution occurs, and the ability to deal with urban environmental pollution incidents is improved. Now there are many cities "significant pollution accident regional early warning system software" [11]. This type of system archives urban pollutant data and uses the accident prediction model of hazardous pollutants in the air, rivers, and lakes, the pollution prediction model of explosion accidents, and the prediction model of mobile pollution accidents. The model establishes the shortest path rescue plan. In order to establish an emergency response system for sudden pollution accidents, it is extremely effective to ensure the development of environmental pollution management in the urban ecological environment management [12].

\subsection{Economic Structure and Level of Economic and Social Development}

In the urban economic structure and social development, its own spatial geographic information is not clear, but in the analysis of the data loading and analysis of the abstract economic factors, the management of the mass data in pairs, various data query functions, such as structure query, element query. Conditional query, fuzzy query, random dynamic query are organically combined with economic, technological, and basic data in the social ecological environment to establish a geographic analysis system that belongs to urban economic statistics. Collect different types and different time periods of urban economic data collected from various channels to summarize and organize them into an economic database to provide data support for provincial or national macroeconomic and technical indicators, and to obtain first-hand information on the level of economic and social development. Enable timely sharing of economic information resources between cities or regions [13].

\section{Conclusion}

To a certain extent, the urban ecological environment management city is to limit the scope and intensity of people's urban development activities; thereby maintaining the structural integrity of the ecological environment system; scientific data analysis and establishing models to predict can enable the development intensity and scope of people's urban activities within the carrying capacity of the ecological environment system. Therefore, geographic information system plays a major role in urban ecological environment management. With the advent of the $5 \mathrm{G}$ era, data has proliferated. It is very rare to extract effective resources from massive data and form an exclusive database platform. Geographical information systems are often regarded as a visualization tool or method. I think geographic information systems are in the current cities. The preliminary work of data collection, data screening, data preprocessing, and data import in 
management is a data processing job of social significance. I believe that the platform database established after investing a lot of human, financial and material resources is increasingly spreading and sharing big data. The more open era will play a huge role in social production, urban management and many other aspects.

\section{Acknowledgements}

This research was supported by SMU Innovation Project of Graduation Student (No. CX2019SZ08).

\section{Conflicts of Interest}

The author declares no conflicts of interest regarding the publication of this paper.

\section{References}

[1] Wang, C.B., Zhang, Y.F., Wu, J.H., Ai, D.X. and Liu, W.J. (2015) Agile Prediction of Potential Emerging Technologies Based on Real-Time Big Data: Enterprise Practice Survey and Research Trend Analysis. Journal of Information, 34, 1173-1180.

[2] McKinsey (2011) Big Data: The Next Frontier for Innovation, Competition, and Productivity.

[3] Shi, X.Q. (2005) Sustainable Urban Ecosystem Management. China Sustainable Development Research Association. China Sustainable Development Research Association. 2005 China Sustainable Development Forum-China Sustainable Development Research Association 2005 Academic Conference Proceedings, Shanghai, September 2005, 59-68.

[4] Ma, N.X. (1998) Several Theoretical Issues in Regional Ecological Environment Assessment. Journal of Northwest University (Natural Science Edition), 4, 57-61.

[5] Novelly (2010) GIS Application in Urban Management at Home and Abroad. https://blog.csdn.net/novelly/article/details/6061457

[6] Wu, T. (2007) Research on the Land Resource Carrying Capacity of Chongming Island Based on GIS and Remote Sensing. East China Normal University, Shanghai.

[7] Bajjali, W. (2018) Using Arcview GIS to Determine the Origin of Groundwater Salinity in the Dhuleil, Halbat and Samra Areas of Jordan. http://gis.esri.com/library/userconf/prov97/to200/pap178/p178.htm

[8] Wei, W.Q. and Yu, J.Y. (1997) Application of Geographic Information System in Hydrology and Water Resources Management. Water Science Progress, 8, 296-300.

[9] Li, H.W. (2009) Research on Ecological Impact Assessment and Ecological Restoration of High-Speed Railway Based on GIS. Central South University, Changsha.

[10] Ni, X.J. (1998) Application of Geographic Information System in Wildlife Research. Bulletin of Biology, 9, 5-8.

[11] Chen, H.M. and Wang, X.Q. (2005) City Air Pollution Diffusion Simulation Analysis: A Taking Fuzhou as an Example. Geoinformation Science, 4, 101-106.

[12] Li, X.X., Shen, Z.X., et al. (2008) Application of Geographic Information System in Environmental Science. Tsinghua University Press, Beijing.

[13] Reid, H.G. (2005) GIS Application in Urban Management. Renmin University of China Press, Beijing. 